\title{
Can Technology Support Teaching for Global Readiness? The Case of the Global Read Aloud
}

\author{
Jeffrey P. Carpenter and Julie Ellison Justice
}

\begin{abstract}
Technology can create new opportunities for learning with and from people of other cultures, not just about them. The Global Read Aloud (GRA) offers an example of such learning possibilities. The GRA is a project that connects classrooms via digital technologies to discuss common texts. This research explored the pedagogical opportunities and challenges associated with using technology to teach for global readiness in the GRA. Although technology broadened how and with whom GRA students read and discussed literature, the depth and quality of technology-facilitated teaching specifically for global readiness was somewhat unclear. We discuss implications for teaching for global readiness.
\end{abstract}

\section{Background}

Schools have often been understood as serving primarily local needs (Tye, 2009), but globalization has made a narrow regional focus outdated. Advancements in information and communication technologies have reduced the distances between peoples and cultures, and education must accordingly prepare students for a future characterized by globalization (Darling-Hammond, 2010; Walsh, 2016). Reflecting this reality, the International Society for Technology in Education Standards for Students (2016) included a global collaborator standard: "Students use digital tools to broaden their perspectives and enrich their learning by collaborating with others and working effectively in teams locally and globally." Various Web 2.0 tools and social media can facilitate changes to when, where, how, and with whom students learn (Krutka \& Carpenter, 2016a), as well as expand opportunities for intercultural and collaborative learning (Peters, 2009). Educators today can leverage technology to facilitate students learning with and from people of other regions and cultures, not just about them (Lock, 2015).

This article analyzes the Global Read Aloud (GRA), an example of an approach to teaching for global readiness that utilizes technology (see https://theglobalreadaloud.com/). Created by U.S. teacher Pernille Ripp in 2010, the GRA exemplifies some of the opportunities and challenges for teaching for global readiness in a digital era. Inspired by a radio story about an online book club, Ripp penned a blog post proposing that educators around the globe join their classrooms in the reading and discussion of a common book (Ripp, n.d.). From these simple origins, the GRA has grown in recent years, with classrooms from more than 60 countries having participated.

The GRA takes place during six weeks in October and November. Participating teachers connect their students with peers from other schools to read and discuss a book. While the first year of GRA included only one book, in subsequent years Ripp has selected multiple texts at different levels, and teachers 
decide which book is most appropriate for their particular context. In 2015, teachers could choose from four books and one picture book author study (see Table 1). The depth and scope of the collaboration between classrooms depends on the participating educators. For example, some teachers pair with one only class, while others partner with several classes.

\section{Table 1}

Global Read Aloud 2015 Book options

\begin{tabular}{lll}
\hline Author & Book & $\begin{array}{l}\text { Recommended } \\
\text { Ages }\end{array}$ \\
\hline Amy Krouse Rosenthal & Various picture books (author study) & All \\
Kevin Henkes & The Year of Billy Miller & Ages 7 and up \\
Lynda Mullaly Hunt & Fish in a Tree & Ages 9 and up \\
L.S. Matthews & Fish & Ages 12 and up \\
Meg Medina & Yaqui Delgado Wants to Kick Your Ass & Ages 14 and up \\
\hline
\end{tabular}

Ripp does not charge any fees to participants in the GRA. Participants register via an online form, and subsequently receive e-mail updates about the GRA. Prior to the GRA, participants use GRA Edmodo and/or Facebook groups to find partner teachers. Ripp provides a rough reading schedule for each of the GRA books. GRA teachers are encouraged to create, discuss, and share lesson plans, resources, activities, and ideas via the technologies of their choice. Typically, students read and discuss the GRA text both within their individual classes, and with their partner classes. During the GRA, students often communicate via synchronous and asynchronous tools including Twitter, Skype, Padlet, and blogs. Many teachers have their classes engage in at least one videoconference session to meet their partner classes. It is also common for students to respond in writing to blog posts and/or questions created by peers from partner classes.

\section{Theoretical Perspectives}

Our lens for understanding the GRA was informed by the construct of teaching for global readiness as defined by Kerkhoff (2017). Drawing upon theories of educational cosmopolitanism (Hansen, 2010; Hull \& Stornaiuolo, 2014) and multiliteracies (Cope \& Kalantzis, 2000; 2009), Kerkhoff (2017) defined global readiness as "global citizenship with the multiliteracies necessary in the 21 st century to participate, collaborate, and work in a global society" (p. 92). Educational cosmopolitanism recognizes universal values, emphasizes critical global citizenship, and encourages open-mindedness and tolerance. Pedagogies that address multiliteracies recognize and embrace the multimodal nature of many modern 
texts, as well as the diverse needs and assets of students. Teaching for such a vision of global readiness is a complex endeavor and Kerkhoff's research suggests it includes at least four elements: situated practice, integrated global learning, critical literacy instruction, and transactional experiences. These four elements of teaching for global readiness provide a helpful lens for considering the opportunities and challenges associated with the use of technology in the GRA.

Situated practice refers to teaching and learning that responds to the contextual nature of learning by attending to the people and place involved. Such practice is relevant, authentic, and social. Situated practice considers the community within the classroom as well as the society within which learning occurs. To be able to respond to their context, teachers must build relationships with students, and seek to understand them as social and cultural beings.

In order to further global readiness, educators design curriculum and instruction that features integrated global learning. Global education should not feature as an extra or special activity, but instead be integrated across grade levels and disciplines. Teachers connect global learning to existing curricula and local matters. Teaching for global readiness demonstrates how the local is already global, and helps students understand how communities around the world are interconnected and interrelated.

Teaching for global readiness also requires the development of students' critical literacy. Educators who teach critical literacy utilize texts from multiple perspectives and help students learn to analyze and evaluate those various perspectives. Kerkhoff sees critical literacy as helping students to "develop the capacity to question the authority of the source of information, analyze the authors' purposes, and locate primary sources" (p. 103).

Finally, transactional experience refers to exchanges of perspective through "reading, writing, listening, speaking, and inquiry experiences ... with diverse others" (p. 103). When students engage in firsthand cross-cultural discussions, they can learn from each other's perspectives. Such direct experiences, be they face-to-face or virtual, are considered essential to the development of intercultural competency. For these firsthand learning experiences to be most beneficial, students must exchange information and ideas with others in ways that require give-and-take from all sides.

\section{Literature Review}

\section{Education for Global Readiness}

The GRA came into being during a time of keen interest in global education (Hull \& Stornaiuolo, 2014; Kerkhoff, 2017). As economies and societies evolve in response to a more interconnected world, the need for schools to prepare global-ready students is apparent (Walsh, 2016). However, consensus is lacking regarding the appropriate goals for a more global educational approach (Peters, 2009; Reynolds, 2015). Different arguments for global education emphasize the importance of preparation for global economic competition, the need for learners to develop "world minded" ways of thinking (Merryfield, Lo, Po, \& Kasai, 2008), and the imperative to educate citizens who engage with global issues 
(Harshman \& Augustine, 2013; Leduc, 2013). Lim (2008) suggests that global education "Should be concerned with more than developing international awareness or a more rounded person; it is also about rights and responsibilities, and duties and entitlement" (p. 1074). The disparate visions of education for global readiness are further muddled by the use of the term global in some cases to signify corporatization or Americanization.

In addition to the absence of clarity regarding purpose, education for global readiness is complicated by other factors including the controversial nature of some global education topics, difficulties with integrating global content into local curricula, and the limited international experience of many educators (Reynolds, 2015; Tye, 2009). Educators must teach for global readiness in ways that counteract potentially ethnocentric or paternalistic attitudes (Leduc, 2013). Global education activities should engage students in critical thinking about global relationships, power dynamics, and systematic inequalities, and situate these matters in relation to local issues. In sum, while there is consistent support for the value of educating for global readiness, it remains a complicated and contested endeavor.

\section{Technology's Roles in Education for Global Readiness}

Historically, constraints of time and place have affected the kinds of learning activities students experience in their schools. However, new possibilities have emerged as Web 2.0 technologies have lessened temporal and geographic obstacles (Carpenter \& Krutka, 2014; 2015; Carpenter \& Green, 2017; Greenhow \& Gleason, 2012; Krutka \& Carpenter, 2016b). Students need not travel abroad to engage in meaningful cross-cultural transactional experiences (e.g., Leask, 2004; Lindsay \& Davis, 2013). Lock (2015) recently suggested that "connecting, communicating, collaborating and creating knowledge with others beyond our local communities have never been more attainable than we are currently experiencing in today's digital world" (p. 140). Digital technologies have facilitated interactions with distant peers that have reportedly led to increases in students' cross-cultural awareness (Krutka \& Carano, 2016), decreases in their ethnocentrism (Union \& Green, 2013) consciousness of their own misconceptions (Pitts \& Brooks, 2016), and greater awareness of their own identity and culture (Myers \& Eberfors, 2010). New technologies also provide learners greater access to experts and diverse forms of expertise (Lock, 2015).

Prior research has described multiple cases of paired higher education classrooms in two different countries interacting over the course of a semester (e.g., Kinchin \& Bryant, 2015; Pitts \& Brooks, 2016). For instance, Krutka and Carano (2016) studied the experiences of students from the Gaza and the United States $(N=16)$ who utilized Skype and Facebook to interact. These technologies reportedly created spaces for humanizing dialogue. For the U.S. students, the opportunity to talk directly with their Gazan counterparts raised their awareness of the human implications of global events; matters in faraway lands "no longer felt like foreign issues because these conflicts involved people who were now near and dear to their heart" (p. 216). Examples of successful small-scale projects that leverage technology to connect K-12 learners have also been documented in the literature (e.g., Barnatt, Winter, Norman, Baker, \& Wieczorek, 2014; Union \& Green, 2013). 
Technological affordances alone do not, however, guarantee the success of global teaching collaborations. Pitts and Brooks (2016) suggested that global education produces the most benefits when learners are "guided through a controlled process of self- and cultural-awareness" (p. 13). The extant literature warns that educators must avoid pitfalls commonly associated with global collaboration. Mere exposure to global opportunities does not inevitably enhance global readiness (Leask, 2004). Learners must critically examine positions of privilege and challenge us vs. them binaries, and consider how differences in the relative power of their respective countries or cultures could affect interactions (Sancho, 2008).

Prior research also suggests educators should avoid one-off learning "events" that are not integrated with regular curriculum. While such events can be gratifying, educators "can get caught up in the excitement ... and enthusiasm" (Pitts \& Brooks, 2016, p. 13) and fail to push students towards critical reflection and self-awareness (Harshman \& Augustine, 2013). Education for global readiness requires sustained learning experiences that can more profoundly affect learning and skill development (Lock, 2015). More sustained forms of global education can allow educators to negotiate differences regarding teaching and learning, as colleagues from different cultures will sometimes have contrasting expectations and perspectives.

Many educators lack relevant personal experiences from their own schooling to inform their teaching for global readiness (Leask, 2004). And while digital technologies can enable new global education activities, some teachers do not have access to those technologies and/or the necessary technology support (Leduc, 2013). Technology thus appears to create both opportunities and challenges for teaching for global readiness. Furthermore, the prior research that has explored education for global readiness has been limited by the small scale of many of the studied interventions, and the paucity of studies in PK-12 settings (Cushner, 2012). Research on a program of the GRA's scale and nature has been missing from the literature.

\section{Method}

\section{Research Questions}

This study sought to contribute to understanding of the pedagogical possibilities arising from organic, technology-intensive global teaching and learning initiatives. The research questions were as follows:

RQ1. What opportunities for teaching for global readiness are associated with the uses of technology in the GRA?

RQ2. What challenges for teaching for global readiness are associated with the uses of technology in the GRA? 


\section{Instrument}

We designed an anonymous online survey that collected data regarding participating educators, their experiences with the GRA, and their perceptions of said experiences (Appendix A). The survey included 27 items split between three parts: informed consent, demographics, and GRA-related items. The survey had open-ended, close-ended, and Likert scale items. We shared an early draft of the survey with the GRA's creator, and three GRA participants from prior years, and revised the draft based on their feedback.

\section{Data Collection}

Upon the conclusion of GRA 2015, we solicited responses to the survey during the following five weeks. Pernille Ripp included a link to the survey in an e-mail sent to the educators who registered for the GRA. We posted multiple survey invitations to social media sites commonly used during the GRA. We sent invitations via Twitter, and included GRA-related hashtags (\#). And we posted invitations to the main Edmodo groups that were created as collaboration spaces for teachers working with the different GRA 2015 books. Across the different online spaces, we distributed invitations at various times and days of the week to make the survey visible to potential participants in different time zones and with varied online habits.

\section{Sample}

Five hundred sixteen participants representing 14 countries responded to the survey, with the vast majority coming from the United States and Canada (Table 2). Ninety-five percent of these educators were females, while $5 \%$ were males. The largest group of respondents was those aged $40-49$ years, who represented almost a third of participants (Table 3). In terms of prior experience, $59.4 \%$ of respondents were participating in the GRA for the first time in 2015. Almost three-quarters of the respondents were regular education teachers, with librarian / media specialists comprising the second largest group of participants (Table 4). While almost 38\% of the respondents were the only individuals in their schools who took part in the GRA, the majority of respondents had colleagues from their school involved with the GRA, including $7.4 \%$ of respondents who had 10 or more GRA participant peers in their schools. Participants worked with students as young as two to as old as 20 , but most commonly taught learners aged 7 to 11 .

70 | LEARNing Landscapes | Autumn 2017, Vol. 11 No. 1 
Table 2

Participant Country of Residence

\begin{tabular}{lll}
\hline Country & Count & Percentage of Respondents \\
\hline United States & 374 & $76.2 \%$ \\
Canada & 89 & $18.1 \%$ \\
Australia & 9 & $1.8 \%$ \\
New Zealand & 7 & $1.4 \%$ \\
United Kingdom & 3 & $0.6 \%$ \\
$\begin{array}{l}\text { Afghanistan, Albania, Argentina, Barbados, Japan, } \\
\text { Poland, Serbia, Spain, Turkey }\end{array}$ & 1 each & $0.2 \%$ each \\
\hline
\end{tabular}

Table 3

Participant Age

\begin{tabular}{lll}
\hline Age & Count & Percentage of Respondents \\
\hline $20-29$ & 49 & $9.5 \%$ \\
$30-39$ & 149 & $28.8 \%$ \\
$40-49$ & 165 & $32.1 \%$ \\
$50-59$ & 123 & $23.9 \%$ \\
60 or older & 29 & $5.6 \%$ \\
\hline
\end{tabular}

Note: Percentages do not sum to $100 \%$ because of rounding.

Table 4

Participant Professional Role

\begin{tabular}{lll}
\hline Role & Count & Percentage of Respondents \\
\hline Regular education classroom teacher & 382 & $74.5 \%$ \\
Teacher librarian / media specialist & 48 & $9.4 \%$ \\
$\begin{array}{l}\text { Instructional technology facilitator or other } \\
\text { technology integration role }\end{array}$ & 17 & $3.3 \%$ \\
Literacy or reading specialist & 15 & $2.9 \%$ \\
Special education teacher & 14 & $2.7 \%$ \\
Instructional coach & 5 & $1.0 \%$ \\
Other & 30 & $5.9 \%$ \\
\hline
\end{tabular}




\section{Table 5}

Response to "Indicate your agreement with the following statement"

\begin{tabular}{llllll}
\hline Question & $\begin{array}{l}\text { Strongly } \\
\text { disagree }\end{array}$ & Disagree & Neutral & Agree & $\begin{array}{l}\text { Strongly } \\
\text { Agree }\end{array}$ \\
\hline I am a frequent user and early adopter & $\mathrm{n}=10$ & $\mathrm{n}=13$ & $\mathrm{n}=49$ & $\mathrm{n}=169$ & $\mathrm{n}=244$ \\
of technology in my teaching. & $2.1 \%$ & $2.7 \%$ & $10.1 \%$ & $34.9 \%$ & $50.3 \%$ \\
& $\mathrm{n}=47$ & $\mathrm{n}=136$ & $\mathrm{n}=97$ & $\mathrm{n}=117$ & $\mathrm{n}=88$ \\
$\begin{array}{l}\text { Apart from the GRA, I facilitate global } \\
\text { Connections for my students. }\end{array}$ & $9.7 \%$ & $28.0 \%$ & $20.0 \%$ & $24.1 \%$ & $18.1 \%$ \\
\hline
\end{tabular}

The GRA appeared to be both similar to and different from the teaching and learning activities the participants typically provided to their students (Table 5). Given that $85.2 \%$ of the participants self-identified as early adopters and frequent users of technology in their teaching, it seems likely that their students were accustomed to some integration of technology into teaching and learning activities. However, fewer than half of the participants (42.2\%) reported that outside of the GRA they facilitated global connections for their students.

\section{Data Analysis}

This article is based primarily on the qualitative survey data, although descriptive statistics also informed the overall analysis. We engaged in a thematic analysis of the qualitative data with the goal of identifying and exploring patterns and themes. We followed a six-phase process of thematic analysis defined by Braun and Clarke (2006): becoming familiar with the data, generating initial codes, searching for themes, reviewing themes, defining themes, and producing a report. To familiarize ourselves with the data and generate our initial codes, we conducted repeated cycles of individual coding followed by discussion of similarities and differences of interpretation. We conducted eight such cycles of coding. Due to the interpretive nature of the qualitative coding in which we engaged, we relied upon intensive discussion to reach agreement on codes, rather than on an interrater reliability statistic (Saldaña, 2016).

We independently read and reread the first 100 survey responses to look for patterns and develop tentative codes. We compared our initial analyses, and through discussion, comparison, and consolidation identified a tentative coding structure that included 53 different codes. We then synchronously coded and discussed the next 100 responses. We grouped and compared data receiving the same codes both to refine our definitions of the codes and to compare and contrast responses. This collaborative coding and discussion led to consideration of various approaches to interpreting the data (Saldaña, 2016; Sandelowski \& Barroso, 2007).

Next, we individually coded the remaining survey responses. After again comparing our coding to reconcile differences of interpretation, we reconsidered the overall code structure. This resulted in the deletion of two codes, and a final set of 51 codes. The full set of responses was again read and coded with the finalized code set. After coding, we prepared summary reports for each qualitative prompt that included data exemplars for 
each code and analysis of code frequencies. After discussion of these individual reports, we identified themes that spanned across various survey items and codes. We then revisited our individual reports in light of these themes, before shifting to the writing of the holistic analysis of results.

\section{Results}

In general, participants reported quite positive perceptions of the GRA (Table 6). In their overall GRA rating, almost $65 \%$ of respondents selected "Outstanding" and $33.2 \%$ chose "Good." Participants also overwhelmingly $(96.5 \%)$ reported that they were interested in participating again in the GRA. In the context of these overall positive perceptions, we will consider below opportunities and challenges for teaching for global readiness associated with the uses of technology in the GRA.

\section{Table 6}

"Rate the overall Global Read Aloud 2015 experience for you and your students."

\begin{tabular}{lll}
\hline Answer & Count & Percentage of Respondents \\
\hline Outstanding & 308 & $64.7 \%$ \\
Good & 158 & $33.2 \%$ \\
Fair & 8 & $1.7 \%$ \\
Poor & 2 & $0.4 \%$ \\
\hline
\end{tabular}

\section{RQ1. What opportunities for teaching for global readiness are associated with the uses of technology in the GRA?}

Analysis of the data most clearly indicated that technology created opportunities for transactional experiences. Participants described a number of ways in which digital tools facilitated student engagement in reading, writing, listening, and speaking experiences with peers from beyond their own schools and districts.

Videoconferencing with partner classes appeared to be a common and valued transactional experience during the GRA. Just under $80 \%$ of the respondents reported that their students used one or both of Skype or Google Hangouts for videoconferencing with another GRA class. Twenty-nine respondents used the word "love" or "loved" to describe student feelings about GRA videoconferencing. Videoconferencing was frequently mentioned as a motivational aspect of the GRA experience. For example, a U.S. middle-school media specialist commented, "The students were able to interact with other students in Canada; it helped to motivate them [students] to create questions and respond to the other students' blogs." Videoconferencing was also credited with contributing to the quality of the connections that occurred during the GRA, as can be seen in the following participant comments: 
"It seemed to impact the students the most when they were able to see the people they were participating within the program."

"The students were able to interact with other students in Canada; it helped to motivate them to create questions and respond to the other students' blogs."

By allowing partner class peers to see each other and interact more directly, videoconferencing appeared to support overall engagement with the GRA.

In particular, "Mystery" Skype and Google Hangout calls were mentioned by $11 \%$ of respondents as an important part of the GRA experience for students. In mystery videoconference calls, the teachers of the two classrooms calling each other have planned the experience and are aware of each other's locations, but the students do not initially know where their peers are. Classes alternate asking each other questions in order to try to figure out their respective locations. A Canadian elementary school teacher commented, "It showed my students that you can connect with the world, with students anywhere and discuss a book."

In addition to synchronous videoconferencing experiences, participants described the use of various digital tools to support asynchronous transactional experiences. Asynchronous communication mitigated some of the challenges that typically hamper collaboration between distant classrooms. Students could post their questions and comments about the GRA books, and receive feedback whenever their partner classes or other participants were online. For example, two respondents described how Twitter and Padlet helped overcome scheduling challenges:

"We were able to connect with lots of classes around the world. The time difference doesn't matter. [Twitter] is quick and replies are quick."

"Padlet allowed us to discuss and interact without worrying about schedules and time zone differences"

Several Padlets were widely shared during the GRA, and sparked responses from classes that were not officially partnered. The widespread use of several GRA-related Twitter hashtags also meant that students' GRA tweets regularly attracted responses.

Digital tools including Edmodo, Google Drive, Kidblog, and Writeabout allowed for extended writing and discussion related to the GRA texts. In contrast to the public nature of Twitter and Padlet, these technologies offered more student privacy and teacher control. Numerous participants described GRA activities that involved students regularly posting their perspectives on their reading to a common online space where peers from partner classes would respond. Students would in turn read and respond to posts from their partner classes. Technology thus gave students a wider audience with which to share their thinking and from which to receive feedback. A second grade teacher wrote that it "was powerful for my reluctant readers and writers to see their ideas shared with others." Another participant commented, "[Students] were very interested in reading other students' ideas or predictions about the books and felt very proud when someone responded to their own." 
Approximately one-fifth of participants referred to using technologies in combination to facilitate transactional experiences. For instance, one teacher wrote, "I felt that the Kidblog offers an ongoing connection with another class, but the Google Hangout was powerful in that we could see the other students," and another participant explained, "One of my classes used Skype to be part of two mystery Skype sessions. They also connected with that same class in Canada with Kidblog. They enjoyed being able to see the other kids they were communicating with." By providing avenues for synchronous and asynchronous communication, and supporting both initial and ongoing connections between participants, technology expanded the possibilities for how and with whom GRA students exchanged perspectives through reading, writing, listening, and speaking experiences.

Although not as prevalent as descriptions of transactional experiences, the data did include instances of integrated global learning related to the GRA. Various participants identified ways in which the GRA connected to their overall curriculum, and did not function as an entirely isolated unit of instruction or special event. For example, one teacher described a Skype session with a class in Australia "where we discussed not only the book, but also made science and geography connections with the other class. It was wonderful to have a meaningful connection that included the book but also went beyond the reading." A respondent who had participated in the GRA for multiple years commented, "The impact of the book and connections leave a mark throughout all subject areas as we often refer back to the book," and another GRA veteran wrote, "The connections to others bring in so many other learning opportunities in every curriculum area." Several respondents anticipated using technology to continue their interactions with their partner classes beyond the GRA, making comments such as the following:

"[The students] are now pen-pals with the class I partnered with and we are continuing our relationship via writing and through the use of technology."

"There was overall enthusiasm for dialoguing with our Canada friends. We even hosted the Canadian teacher in Florida during her spring break. It is a tie that will last forever."

A handful of respondents specifically mentioned connecting GRA activities to social studies standards and geography content. Multiple participants mentioned how videoconferencing piqued their students' interests regarding the locations of partner classes, making comments such as the following:

"Several of my students want to research the places we've Skyped with."

"The mystery Skype got them really excited about map skills."

"They've also become more interested in connecting with other students globally and learning about other countries."

In some cases, teachers appeared to recognize opportunities for integration of the GRA with their overall curriculum during or after the GRA, rather than having planned in advance for such integration. For example, one U.S. participant wrote, "I hope to extend our learning with some geography lessons as a result of the postcards we received," while a Canadian teacher commented, "We still have much to do with this event even though it is technically wrapping up. I feel like it is the beginning of many things." 
Jeffrey P. Carpenter and Julie Ellison Justice

\section{RQ2. What challenges for teaching for global readiness are associated with the uses of technology in the GRA?}

Although technology appeared to create opportunities for teaching for global readiness in the GRA, our data suggested that challenges were also experienced. Participants most commonly mentioned encountering challenges related to integrated global learning. Almost one-third of respondents (32\%) identified curricular barriers they experienced during their implementation of the GRA. The two most frequently mentioned curriculum challenges to the integration of the GRA with other content and local matters were time pressures and the rigid nature of curriculum. Many participants mentioned feeling that they lacked sufficient time to give the GRA the full attention it deserved. For instance, one participant commented, "I would have loved to do even more with it than I did but other curricular demands wouldn't allow it," while another educator wrote, "I wanted to spend a lot of time on it, but that of course takes away from other necessary instructional time."

Participants noted how pacing guides, standardized testing, and curricular mandates competed with their desire to dedicate time to the GRA. A teacher wrote, "We are tasked with an immense number of things we must accomplish each day, combined with the ever-present push of standardized testing almost every four weeks." Another respondent saw opportunities to "teach the weekly grammar, phonics, fluency, writing, and comprehension skills and strategies required in our reading curriculum through the GRA books," but could not do so because "our time and what we teach is typically very dictated to us." This educator was thus reduced to "trying to squeeze in these extra [GRA] lessons." A second respondent used similar language in describing obstacles to the integration of the GRA with her regular curriculum:

We have pacing guides for every subject area and I was challenged with finding the time to squeeze in the activities. I know how much more valuable the GRA is compared to many of our requirements but I often felt guilty for allowing my students extra time for activates related to the GRA.

While technology created possibilities for new kinds of teaching and learning activities during the GRA, some teachers found it difficult to integrate the GRA with their existing curricula. When the GRA felt like an extra or special activity, rather than a part of the regular curriculum, other curricular demands made many respondents feel they could not dedicate sufficient time to the GRA. Policies around curriculum may therefore have limited opportunities for teachers to use technology to teach for global readiness during the GRA.

Participants also reported challenges associated with trying to use technology to facilitate transactional experiences during the GRA. The most commonly mentioned obstacle to transactional experiences was time zone differences that complicated attempts to participate in synchronous videoconference activities. For example, a teacher from Australia wrote, "Unless it's a New Zealand school we have next to no chance to Skype people." Other similar comments included the following:

"I would have loved to connect overseas but the time difference makes it difficult." 
"It is hard to collaborate with other teachers in different time zones and with different school schedules! Teaching is a tough enough business, and to organize a collaboration is a huge extra task!"

Schedules sometimes presented a more general challenge to GRA partnerships between classrooms, with school systems in different regions and countries featuring varied class period and term lengths, as well as observing different holidays. For example, teachers could not as easily engage their students in transactional experiences with far-flung peers in the following scenarios:

"Our school schedule did not align with the GRA. We had standardized testing and a fall break that interrupted our reading."

"We start in late July and end 1st quarter in late September or early October, right when GRA starts. Because of this, for the past four years, we've been playing 'catch up' the first week we return for second quarter. We aren't able to connect with schools from the very start of the book."

Some GRA participants thus faced various obstacles in coordinating the synchronous and/or asynchronous technology-facilitated interactions that appeared to be so beneficial for many GRA students.

Some participants also directly mentioned policies around technology as presenting challenges during their GRA experiences. A handful of respondents reported that regulations or administrator decisions had prevented them from using particular digital tools during the GRA, including Skype, Edmodo, Kidblog, and Write About. One participant explained, "I wasn't allowed to blog outside of an approved platform," and another said of her administrators, "They fear private information being used and children being placed at risk."

\section{Discussion}

Our findings describe educators' perceptions of pedagogical opportunities and challenges associated with a technology-rich approach to global education. The technologies used in the GRA demonstrated the potential to bridge divides between people by enabling the sharing of different perspectives across time and space. The GRA appeared to expand spaces for transactional learning experiences beyond the physical classroom. Our findings related to the role of videoconferencing in the GRA align with previous studies that have described the contributions videoconferencing can make to social presence and community building in cross-cultural projects (Krutka \& Carano, 2016; Wang, 2011).

The GRA demonstrates how technology can support a low-cost, participant-driven initiative that opens up more classrooms to direct interaction with diverse peers. However, it was apparent that participants experienced both opportunities and challenges as they sought to integrate GRA transactional experiences with their regular curricula. While the GRA is designed to allow participating teachers a great deal of flexibility, the contexts within which participants work may include more rigid expectations. Technology appeared to help empower teachers to self-organize and customize the GRA to meet their and their students' needs, but some teachers still faced certain requirements that complicated their efforts to take 
full advantage of the GRA. In some cases, curricula and associated mandates may not be keeping up with the pedagogical possibilities offered by new technologies.

The participants' responses to our survey left it somewhat unclear how technology was utilized to support situated practice and critical literacy instruction. Few participant comments addressed either opportunities or challenges associated with these aspects of teaching for global readiness. Considering that almost $60 \%$ of the respondents were first time GRA participants, it may be that many teachers were not yet experienced enough with the GRA to pursue instruction that included more attention to situated practice and/or critical literacy. For example, teachers who were partnering their classes for the first time may not have felt immediately comfortable or knowledgeable enough to tackle potentially thorny issues related to critical literacy. While technology might make it fairly easy for two partnered classes to engage in an introductory Mystery Skype call, their teachers might feel less equipped to lead Skype discussions among their students that might touch upon, for example, a past conflict in which the countries of the partnered classes were on opposing sides or a contentious contemporary issue that might spur strong disagreements between students. Other GRA teachers could require guidance on how to engage more with the diversity that exists within their own schools and local communities (Charles, Longerbeam, \& Miller, 2013).

Digital technologies can be a double-edged sword, providing new opportunities for teaching and learning, but also asking more of teachers (Meabon Bartow, 2014), and the GRA appears to be a project in which this is the case. More professional development and support could be necessary to help maximize the benefits of projects such as the GRA. For instance, while one participant might need help with the technical features of a certain videoconferencing tool, a second participant could instead require support in order to engage students in meaningful dialogue during a videoconference session, and a third might need assistance in reflecting upon cultural differences that emerged during a videoconference session. In the absence of such supports, there is a real possibility that GRA activities could in some cases actually negatively affect students' global readiness. Instead of broadening students' worldviews, interactions with those perceived as other can potentially lead to the entrenchment of existing stereotypes (Pitts \& Brooks, 2016). Educators must therefore be thoughtful in how they utilize the opportunities for cross-cultural contact provided by technology, and should reflect upon areas in which they may need to expand their own professional knowledge and skills.

\section{Limitations}

This research is limited by its reliance upon convenience sampling and a self-report survey. Participants may not represent trends in the general educator population, and were possibly among the more enthusiastic GRA participants. Educators who experienced intense challenges may have failed to complete the full GRA program and would thus have been likely to see or respond to our end-of-program survey. The fact that participants were overwhelmingly from the United States and Canada could also limit the applicability of these findings to the experiences of teachers in contexts outside of North America. 


\section{Implications for Practice and Research}

Despite its limitations, this research has implications for the field and suggests potential topics for future research. Given the generally positive participant experiences, educators interested in teaching for global readiness may want to consider participating in future GRAs. Educators who do participate in future GRAs should consider how they best integrate the project with the rest of their curriculum in a situated and critical fashion. It is likely, however, that many educators will need support as they seek to manage such interactions, particularly educators who are not as tech-savvy and globally minded as our participants. Participants will require multifaceted and individualized support to meet their varied pedagogical, technological, and content area needs. Curriculum facilitators might help teachers determine how to integrate experiences like the GRA with existing curriculum mandates. Teacher educators also should consider how best to prepare the next generation of teachers to take advantage of and even create opportunities such as the GRA.

Research that compares organic, teacher-led initiatives like the GRA with more structured global education programs that are run by nonprofit, for-profit, and government-supported organizations would also benefit the field. Future research might study whether and how GRA participation affects teaching and learning after the program. For example, does GRA participation lead teachers to integrate more global approaches throughout the remainder of the school year? Research could examine cases in which classes partnered during the GRA subsequently collaborate in additional ways, or study partnerships between teachers that have spanned multiple GRA iterations. Measures other than teacher self-report surveys could provide more accurate understanding of how projects such as the GRA affect student achievement and global readiness. Asking students directly about their GRA experiences could yield more insight into how students' experience such cross-cultural projects. Researchers might explore the experiences of GRA teachers at schools with large numbers of participating educators and students. Such clusters of teachers may have quite different experiences than individual educators who could be hindered by the absence of local administrative support for a bottom-up innovation like the GRA (Petko, Egger, Cantieni, \& Wespi, 2015). Finally, future studies could also delve into how projects such as the GRA might tap the potential for text-to-speech and translation technologies to work in concert to support cross-cultural understanding among learners who lack a common language (e.g., Lewis, 2015; Shadiev \& Huang, 2016).

\section{Conclusion}

Students today must interact with different cultures and global issues if they are to become the responsible citizens the world needs. New approaches to teaching and learning that develop students' global readiness are needed, and technology has shown the potential to make the "other" feel less distant and foreign. Technology can extend the possibilities for learners to share their perspectives, and co-construct knowledge and understanding with far-flung peers. One-book, one-school programs have encouraged the shared reading of books across classrooms, but technology has allowed for the expansion of such activities to an even larger scale in the GRA. However, while digital tools may offer possibilities for 
teachers to welcome the world into their classrooms, the new experiences technology can facilitate also bring with them certain curricular and pedagogical challenges.

\section{References}

Barnatt, J., Winter, M., Norman, V., Baker, D., \& Wieczorek, S. (2014). Using cultural artifacts to understand self and other: A global exchange in elementary classrooms. The Ohio Social Studies Review, 51(1), 7-17.

Braun, V., \& Clarke, V. (2006). Using thematic analysis in psychology. Qualitative Research in Psychology, 3(2), 77-101. doi:10.1191/1478088706qp063oa

Carpenter, J. P., \& Green, T. D. (2017). Mobile instant messaging for professional learning: Educators' perspectives on and uses of Voxer. Teaching and Teacher Education, 68, 53-67.

Carpenter, J. P., \& Krutka, D. G. (2014). How and why educators use Twitter: A survey of the field. Journal of Research on Technology in Education, 46(4), 414-434.

Carpenter, J. P., \& Krutka, D. G. (2015). Engagement through microblogging: Educator professional development via Twitter. Professional Development in Education, 41(4), 707-728.

Charles, H., Longerbeam, S. D., \& Miller, A. E. (2013). Putting old tensions to rest: Integrating multicultural education and global learning to advance student development. Journal of College and Character, 14(1), 47-58.

Cope, B., \& Kalantzis, M. (Eds.). (2000). Multiliteracies: Literacy learning and the design of social futures. New York, NY: Routledge.

Cope, B., \& Kalantzis, M. (2009). Multiliteracies: New literacies, new learning. Pedagogies: An International Journal, 4(3), 164-195.

Cushner, K. (2012). Intercultural competence for teaching and learning. In B. Shaklee, \& S. Baily (Eds.), A framework for internationalizing teacher education (pp. 41-59). Lanham, MD: Rowman Littlefield.

Darling-Hammond, L. (2010). The flat world and education. New York, NY: Teachers College Press.

Greenhow, C., \& Gleason, B. (2012). Twitteracy: Tweeting as a new literacy practice. The Educational Forum, 76(4), 464-478.

Hansen, D. T. (2010). Cosmopolitanism and education: View from the ground. Teachers College Record, $112,1-30$.

Harshman, J. R., \& Augustine, T. A. (2013). Fostering global citizenship education for teachers through online research. Educational Forum, 77(4), 450-463.

Hull, G. A., \& Stornaiuolo, A. (2014). Cosmopolitan literacies, social networks, and "proper distance": Striving to understand in a global world. Curriculum Inquiry, 44(1), 15-44.

International Society for Technology in Education (2016). Standards for students. Retrieved from http://www.iste.org/standards/standards/for-students-2016 
Kerkhoff, S. N. (2017). Designing global futures: A mixed methods study to develop and validate the teaching for global readiness scale. Teaching and Teacher Education, 65, 91-106.

Krutka, D. G., \& Carano, K. T. (2016). "As long as I see you on Facebook I know you are safe": Social media experiences as humanizing pedagogy. In A. R. Crowe \& A. Cuenca (Eds.), Rethinking social studies teacher education in the twenty-first century (pp. 207-222). New York, NY: Springer International Publishing.

Krutka, D. G., \& Carpenter, J. P. (2016a). Why social media must have a place in schools. Kappa Delta Pi Record, 52(1), 6-10.

Krutka, D. G., \& Carpenter, J. P. (2016b). Participatory learning through social media: How and why social studies educators use Twitter. Contemporary Issues in Technology and Teacher Education, 16(1), 38-59.

Leask, B. (2004). Internationalisation outcomes for all students using information and communication technologies (ICTs). Journal of Studies in International Education, 8(4), 336-351.

Leduc, R. (2013). Global citizenship instruction through active participation: What is being learned about global citizenship? Educational Forum, 77(4), 394-406.

Lewis, W. D. (2015). Skype translator: Breaking down language and hearing barriers. Proceedings of Translating and the Computer (TC37). Retrieved from https://www.microsoft.com/enus/research/publication/skype-translator-breaking-down-language-and-hearing-barriers/

Lim, C. P. (2008). Global citizenship education, school curriculum and games: Learning Mathematics, English and Science as a global citizen. Computers \& Education, 51(3), 1073-1093.

Lindsay, J., \& Davis, V. (2013). Flattening classrooms, engaging minds: Move to global collaboration one step at a time. Upper Saddle River, NJ: Pearson.

Lock, J. V. (2015). Designing learning to engage students in the global classroom. Technology, Pedagogy and Education, 24(2), 137-153.

Meabon Bartow, S. (2014). Teaching with social media: Disrupting present day public education. Educational Studies, 50(1), 36-64.

Merryfield, M. M., Lo, J. T. Y., Po, S. C., \& Kasai, M. (2008). Worldmindedness: Taking off the blinders. Journal of Curriculum and Instruction, 2(1), 6-20.

Myers, J., \& Eberfors, F. (2010). Globalizing English through intercultural critical literacy. English Education, 42(2), 148-170.

Peters, L. (2009). Global education: Using technology to bring the world to your students. Eugene, OR: International Society for Technology in Education.

Petko, D., Egger, N., Cantieni, A., \& Wespi, B. (2015). Digital media adoption in schools: Bottom-up, top-down, complementary or optional? Computers \& Education, 84, 49-61.

Pitts, M. J., \& Brooks, C. F. (2016). Critical pedagogy, internationalisation, and a third space: Cultural tensions revealed in students' discourse. Journal of Multilingual and Multicultural Development, 38(3), 251-267. doi:10.1080/01434632.2015.1134553 
Reynolds, R. (2015). One size fits all? Global education for different educational audiences. In R. Reynolds, D. Bradbery, J. Brown, K. Carroll, D. Donnelly, K. Ferguson-Patrick, \& S. Macqueen (Eds.), Contesting and constructing international perspectives in global education (pp. 27-41). Rotterdam, Netherlands: Sense Publishers.

Ripp, P. (n.d.). The history of the Global Read Aloud [blog]. Retrieved from https://theglobalreadaloud.com/info-for-2015/the-history-of-the-global-read-aloud/

Saldaña, J. (2016). The coding manual for qualitative researchers (3rd ed.). London, UK: Sage.

Sancho, J. M. (2008). Opening students' minds: Educational technology in a growing internationalised world." In M. Hellstén \& A. Reid (Eds.), Researching international pedagogies (pp. 259-276). Dordrecht, Netherlands: Springer.

Sandelowski, M., \& Barroso, J. (2007). Handbook for synthesizing qualitative research. New York, NY: Springer Publishing Company.

Shadiev, R., \& Huang, Y. M. (2016). Facilitating cross-cultural understanding with learning activities supported by speech-to-text recognition and computer-aided translation. Computers \& Education, 98, $130-141$.

Tye, K. (2009). A history of the global education in the United States. In T. Fuss Kirkwood-Tucker (Ed.), Visions in global education (pp. 3-24). New York, NY: Peter Lang.

Union, C., \& Green, T. (2013). The use of web 2.0 technology to help students in high school overcome ethnocentrism during global education projects: A crosscultural case. The Georgia Social Studies Journal, 3(3), 109-124.

Walsh, L. (2016). Educating generation next: Young people, teachers and schooling in transition. Houndsmill, UK: Palgrave Macmillan.

Wang, C. M. (2011). Instructional design for cross-cultural online collaboration: Grouping strategies and assignment design. Australasian Journal of Educational Technology, 27(2), 243-258. 


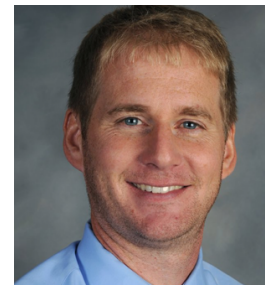

Jeffrey P. Carpenter is an Associate Professor of Education and Director of the Teaching Fellows program at Elon University in Elon, North Carolina. He taught middle school and high school English and ESOL for 10 years in the United States, Japan, and Honduras. He researches, theorizes, and teaches about new and innovative modes of student and teacher learning. In particular, he is interested in ways by which collaborative technologies facilitate the teaching and learning process. His work has been published in journals including Computers \& Education, The Internet \& Higher Education, and Teaching \& Teacher Education.

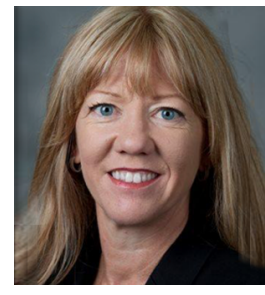

Julie Ellison Justice is an Assistant Professor of Education at Elon University, focusing on literacy development and literacy education policy. As a teacher, she aims to help preservice teachers engage critically with literacy practices both in the classroom and in the global community. As a scholar, she has published in the areas of preservice teacher education and technology, literacy policy, and young children's literacy development. Her current scholarship is situated at the intersections of literacy development, literacy policy, technology, and children's literature. She recently coedited the book Becoming Critical Teacher Educators: Narratives of Disruption, Possibility, and Praxis, published by Routledge Press in 2017.

\section{Appendix A}

Survey Items

Including Global Read Aloud 2015, how many times have you and your students participated in the Global Read Aloud?

Including yourself, how many teachers at your school participated in the Global Read Aloud 2015?

How did you and your class read the book? (Please check all that apply).

We read aloud with another class using a video conferencing service such as Skype, Google Hangout, Facetime, etc. (1)

Teacher read aloud to the whole class during class time. (2)

Children read aloud to each other, within their own class, during class time. (3)

Children read silently on their own. (4)

Parents were expected to read to children at home. (5)

Other (6)

Please indicate technologies your students utilized as part of their Global Read Aloud 2015 activities.

Twitter (1) Edmodo (2) Skype (3) Google Hangout (4) Google Drive (5) Instagram (6)

Padlet (7) Writeabout.com (8) Tackk (9) Sway (10) Kidblog (11) Goodreads (12) Voxer (13)

Email (14) Flipgrid (15)

Other (16) 
Which technology was most important to your students' GRA experience? Why?

Please indicate technologies you, the teacher, utilized as part of your organization, planning, and teaching of the Global Read Aloud 2015. (Check all that apply).

Twitter (1) Edmodo (2) Skype (3) Google Hangout (4)

Google Drive (e.g., Google docs, forms, sheets) (5) Voxer (6) Writeabout.com (7)

Facetime (8) Email (9) Facebook (11)

Other (10)

Which technology was most important for you? Why?

Please indicate your degree of disagreement or agreement with the following items.

\begin{tabular}{|c|c|c|c|c|c|}
\hline & $\begin{array}{c}\text { Strongly } \\
\text { disagree (1) }\end{array}$ & $\begin{array}{c}\text { Disagree } \\
(2)\end{array}$ & $\begin{array}{c}\text { Neutral } \\
(3)\end{array}$ & $\begin{array}{l}\text { Agree } \\
(4)\end{array}$ & $\begin{array}{l}\text { Strongly } \\
\text { Agree (5) }\end{array}$ \\
\hline $\begin{array}{l}\text { My students are generally highly } \\
\text { motivated and engaged. (1) }\end{array}$ & O & O & O & O & 0 \\
\hline $\begin{array}{l}\text { My students were highly } \\
\text { motivated and engaged during } \\
\text { their Global Read Aloud (GRA) } \\
2015 \text { activities. (2) }\end{array}$ & O & O & O & O & O \\
\hline $\begin{array}{l}\text { My students liked the GRA } \\
\text { book. (3) }\end{array}$ & O & O & o & O & O \\
\hline $\begin{array}{l}\text { My students liked interacting } \\
\text { with students from other schools } \\
\text { as a part of the GRA. (4) }\end{array}$ & O & $\mathrm{O}$ & $\mathrm{O}$ & $\mathrm{O}$ & $\mathrm{O}$ \\
\hline $\begin{array}{l}\text { I am a frequent user and early } \\
\text { adopter of technology in my } \\
\text { teaching. (5) }\end{array}$ & O & O & O & $\mathrm{O}$ & $\mathrm{O}$ \\
\hline $\begin{array}{l}\text { I consider literacy and/or } \\
\text { reading instruction one of my } \\
\text { strengths as a teacher. (6) }\end{array}$ & O & O & O & $\mathrm{O}$ & O \\
\hline $\begin{array}{l}\text { I read aloud to my students } \\
\text { frequently. ( } 7 \text { ) }\end{array}$ & O & O & O & O & O \\
\hline $\begin{array}{l}\text { Apart from the GRA, I } \\
\text { collaborate with educators } \\
\text { outside of my school. (8) }\end{array}$ & $\mathrm{O}$ & O & O & O & O \\
\hline
\end{tabular}


Apart from the GRA, I facilitate global connections for my students. (9)

The GRA is similar in nature to other teaching and learning experiences I provide for my students. (10)

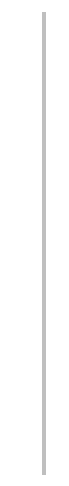

Rate the overall Global Read Aloud 2015 experience for you and your students.

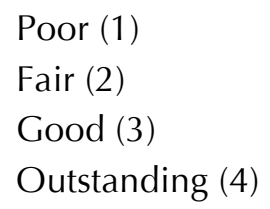

Will you participate in future Global Read Alouds?

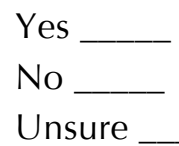

Why did you participate in the Global Read Aloud 2015?

How did the Global Read Aloud 2015 impact your students' learning?

What was the biggest obstacle or challenge you faced with the Global Read Aloud 2015?

Tell us your favorite moment from your and your students' participation in the Global Read Aloud 2015.

What changes or improvements would you recommend for the next Global Read Aloud? 
Jeffrey P. Carpenter and Julie Ellison Justice

86 | LEARNing Landscapes | Autumn 2017, Vol. 11 No. 1 